\title{
Toxic Toxteth: understanding press stigmatization of Toxteth during the 1981 uprising.
}

\author{
BUTLER, A.
}

2020

(C) The Author(s) 2019 


\section{Introduction}

Smashed windows, looted shops, terrorised local inhabitants, burning cars, buildings on fire, policemen rolling over and over to extinguish the flames on their tunics and hair, petrol bombs, flying bricks, the ranks of incongruous British bobbies trembling behind their riot shields, hopelessly ill-equipped, both mentally and physically, for the hatred that confronts them (Guardian, 1981a).

On $3^{\text {rd }}$ July 1981, an uprising ${ }^{1}$ broke out in Toxteth, Liverpool. Sporadic violence continued for several weeks throughout the summer. The uprising wrought $f_{11}$ million of damage to the area, a disabled man was killed by the police, and both civilians and police were injured (Murden, 2006: 444). Undoubtedly, the uprising of 1981 was a key moment in Toxteth's history but, in this paper, I examine how press coverage at this crucial moment led to the stigmatization of Toxteth. I question how media stigmatizes place, and how the media influences the way we view the world. To do this, I build on the work of Hastings (2004) and Devereux et al. (2011a; 2011b) who acknowledge that not enough has been done to understand the production of stigma. Hastings considers the role of discourse in constructing a stigmatized vision of housing through regeneration literature but Devereux et al. turn to the role of the media discourse. They note that the media contribute to territorial stigmatization by using a pathologizing discourse, which focuses on "residents as possessing deviant norms and values, which represent a threat to mainstream culture" (Devereux et al, 2011a: 125).

Territorial stigmatization, a term coined by Loïc Wacquant, refers to the stigma attached to particular places. Wacquant's framing of stigma relies on the temporal hold of advanced marginality and, he argues that territorial stigma can latch onto existing forms of racial or povertybased stigma (2007: 67). As a poor and ethnically diverse area, the stage was set for the adherence of place-based stigma in Toxteth. In this paper, I look at the uprising as a defining moment in Toxteth's history and examine how press reporting during and immediately following the uprising stigmatizes Toxteth in four ways: through naming, negativity, oppositionality, and strangermaking. The process of naming refers to the journalistic 'creation' of the idea of Toxteth. Negativity is characterized by a lack of positive features, a smearing of place through the 'from

\footnotetext{
${ }^{1}$ While the media portray the events of 1981 as 'riots', I elect to refer to them as 'uprising' reflecting local terminology (Hughes, 2018, interview). This difference in local/official terminology is echoed in Darnell Hunt's work on the Los Angeles 'riots' (1997).
} 
above' application of unfavourable imagery, language, or semantic/syntactic choices. I have borrowed the term 'oppositionality' from the field of psychology to explain the way that the press frames Toxteth and its residents as being wilfully hostile and contrary to the mainstream. My conception of "stranger-making" draws on Georg Simmel's work on the figure of the stranger in society, and I use the concept to explain how the press spatially fixes Toxteth while socially distancing the district and its residents.

Through a combined quantitative and qualitative content analysis that draws on the critical discourse analysis (CDA) tradition, I analysed 496 articles from five British newspapers (the Express, the Guardian, the Times, the Mirror, and the Financial Times) sampled from between July $3^{\text {rd }}$ 1981 and December $31^{\text {st }} 1981$ to see how Toxteth was framed over this six-month period, which incorporates the coverage both during and in the six months following the uprising. I show that the press largely constructed the name of Toxteth, and that while externally imposing an identity on Toxteth, they deny Toxteth residents a voice and a means of self-definition. Fewer than 10\% of all articles in this study quote a resident, raising questions about who gets to speak, who gets to define identity, and how this feeds into a stigmatizing process that externally smears a location.

The paper begins with a review of the literature of media stigmatization before discussing the research design. It then turns to a consideration of Liverpool and Toxteth's stigmatized image before presenting my findings and a discussion of how the press constructs a stigmatizing and pathologizing image of Toxteth in 1981. The paper concludes by suggesting that if the media sought to 'give voice to the voiceless', a more equitable, less stigmatizing press could emerge.

\section{Media representation of stigmatized places}

The media play a strong role in understanding the world around us according to agenda setting theory and the propaganda model, the latter of which highlights a closeness between the interests of the powerful elites that rule the media, and other powerful elites in society such as politicians (McCombs and Shaw, 1968; Herman and Chomsky, 2010). The media, according to Herman and Chomsky, functions as a corporation based on a profit motive and also seeks to uphold the status quo in which it is enmeshed with other powerful elites and agents of power. Reflecting this social and political position, the media puts forth messages of society's powerful elites that facilitate the consent of the public and the upholding of the ideological status quo. 
Though sometimes this is an unconscious process, Teun van Dijk explains that reporters and editors use 'models' to put forth a particular vision of society. Journalists and editors can affect the way that readers construct these models through the language used and the framing of events for various reasons. Van Dijk points out that journalists have their own model of the events that they report and it is the aim of a news report and its authors that the readers form a model of the news event in the report' (1996: 14) and that 'one of the many ways to influence the structure of a model (and hence, the understanding of a news event) is to manipulate what information is important' (1996: 14). The result is that reporters can structure their texts in such a way that it leads readers to create a particular model or image of a situation, person or place; stigmatizing language in the media results in a stigmatizing view of aspects of the world around us. Of course, how readers react and respond to the text varies, but research suggests that stereotypes or stigmatizing coverage in the media results in a reproduction of these attitudes in quotidian life (Schemer, 2012) and that objective interpretation is suffocated by the elite domination of the media (Herman and Chomsky, 1988: 2).

Devereux et al. consider how the discourse of stigma is formed in the press (2011a; 2011b). They consider the role of local and national Irish media in constructing and reproducing a stigmatized identity of Moyross, a housing estate near Limerick, Ireland. They note that media, when discussing place, tend to employ a pathologizing gaze (Devereux et al., 2011b), meaning that reporters largely ignore potential structural explanations for an area's character and, instead, blame those within the area for its perceived problems. To do otherwise and to adopt a structural criticism would be to criticise the status quo in society and doing so would jeopardise the media's powerful position within this socio-political structure. The result is damaging for a place and its population; by shifting the gaze away from externally-imposed or structural problems, the media perpetuate the view that nobody but the residents in an area are responsible firstly for its demise but secondly and, more importantly, for the amelioration of the situation. This discourse shuts down debate and leads readers to shape their vision of places in a certain, stigmatized manner.

This is perpetuated by the fact that it is unusual for the media to feature positive stories of a stigmatized place (Tsfati and Cohen, 2003; Devereux et al., 2011a; 2011b). Instead, reporters, often due to the economic constraints of their paper that demand sales (van Dijk, 1996: 25), report negative stories that hint at controversy and strife (Devereux et al., 2011a: 129) because these stories are newsworthy (Galtung and Ruge, 1965: 68). Even overtly positive stories tend to 
reference negative associations in order to conform with the marketized system of newspaper production where sales are imperative to the newspaper's existence (Devereux et al., 2011b: 504).

\section{Methods}

I selected newspapers for analysis based on a broad spectrum of political leanings and markets to ascertain a full picture of coverage and views (Hartmann and Husband, 1974: 128). The Times and Express represent broadly right-of-centre political leanings, and the Guardian and Mirror are broadly left-leaning. The Express and Mirror pursued tabloidization early with the Mirror embracing the style in 1934 and seeking to be a 'brash tabloid aimed directly at a working-class audience' (Bingham and Conboy, 2015: 14). In 1977, the Express followed the tabloid model to try and boost sales (Bingham and Conboy, 2015: 19). The Times and the Guardian, however, have traditionally been broadsheet papers but, since the 1980s they have embraced elements of tabloidization including reduced page size, increased page volume, and soft news coverage (Bingham and Conboy, 2015: 230). The Financial Times is included to reflect Noam Chomsky's assertion that it is the paper that 'tells the truth' (Kennard, 2013).

As part of a larger project that considers the stigma applied to Toxteth throughout the $20^{\text {th }}$ century, I reviewed all articles for relevance, which yielded a final sample of 1,950 texts. Each article was assigned a code and entered into a coding schedule based on that of Bryman (2012). The coding schedule consisted of columns to note the article's code number, title, page number, author, news type (hard news, feature, opinion etc.), code (how Toxteth was mentioned), sub-code, tag words, descriptors, valence (whether Toxteth was mentioned in a positive or negative angle ${ }^{2}$ ), quote source, and comments, which amounted to a summary of the article. For this section of the study, I further constrained the data to the dates between the start of the uprising on July $3^{\text {rd }} 1981$ and the end of that calendar year (December $31^{\text {st }} 1981$ ) resulting in a sample of 496 texts across all five papers (43 in the Express, 31 in the Mirror, 4 in the Financial Times, 222 in the Times, and 196 in the Guardian). The initial analysis involved studying elements within the text: frequency of word use; themes used; grammar and symbolic language; and the use of tag-phrases. A second analysis followed, and sought to connect the intratextual elements with broader ideology and political discourse. At this stage, several key themes that are discussed in this paper became evident.

\footnotetext{
2 Although overwhelmingly negative in valence, positive articles would have been those that told of community enterprise, spirit or success without making negative associations.
} 
The textual analysis was complemented by a series of 12 interviews with reporters who wrote some of the articles under study, with media commentators, and politicians who were active at the time of the uprising. Elements of these interviews are featured in the findings sections of this paper. Some of those interviewed were happy to be named publically whereas others spoke on condition of anonymity.

\section{Pariah city: ${ }^{3}$ Liverpool's image}

Liverpool is a stigmatized city in 'plays, television drama, autobiographies, disaster texts, articles, features, comment pieces, editorials, chat shows, news items, political interviews and reviews' (Scraton, 2007: 77). Television dramas and plays such as Boys from the Blackstuff, Dockers, Liver Birds, and Our Day Out, together with Harry Enfield's 'calm down' Scouse parody all serve to depict a stigmatizing view of the city. Vastly different in their intentions, Enfield's sketches are purely caricature and raise questions of class representation, while Alan Bleasdale's Boys from the Blackstuff was created to highlight the structural plight afflicting Liverpool. Nevertheless, both distil the essence of Toxteth into a stereotyped model of social strife, decline, and despair. Many of these negative portrayals have their roots in the economic decline of the 1970s and 1980s that negatively affected Liverpool (Boland, 2008: 356), and are in line with the dominant ideology that Liverpool was a place of danger to the rest of the country which should, according to Chancellor of the Exchequer Geoffrey Howe (1979-1983), be shut down through a managed decline (Howe, 1981). Despite years passing since the downturn of the 1970s and 80s, Liverpool remains a highly stigmatized city (Madsen, 1992: 633). Boland details the image and planning campaign that has seen the city rebranded publically as the City of Culture, in contrast to its mid-20 $0^{\text {th }}$ century image (2013). Nevertheless, the popular reputation of Liverpool is one of low-skilled labour, deflated economic prospects, and a history of precarity, riots, and crumbling industry (Madsen, 1992; Boland, 2008).

Toxteth, in particular, bears a scarred image. Located in the south end of Liverpool in the Liverpool 8 postmark, Toxteth was once separate to the city of Liverpool but was incorporated into the expanding city in 1895 (Belchem, 2006: 515). Prior to its incorporation into the city of Liverpool, Toxteth Park as it was then known, was a mixed but wealthy area, home to Liverpool's booming merchant class (Cooper, 1985: 60). Grand boulevards lined by equally grand houses,

\footnotetext{
${ }^{3}$ This term is borrowed from Wilks-Heeg's piece on Liverpool's history.
} 
however, fell into disrepair and were rented out as lodgings once incorporated into the city. Toxteth was also home to the black population of Liverpool, some of whose ancestors had arrived as slaves and others who were foreign seamen (Hunt, 2014: 391). By 1919, Toxteth was known in the press as the 'New Harlem' of Liverpool in reference to the traditionally African American area of New York City (Belchem, 2000: 29). It remained a racially diverse area with a high black population during the 20th century; by the 1970s Margaret Simey, a local councillor and chair of the Merseyside County Police Committee described Toxteth as a 'dumping ground' into which most working poor and Black residents of Liverpool were consigned to live (Nassy Brown, 2005: 68). The Liverpool-born Black population of Liverpool has consistently been marginalised through institutional racism and stereotypes, often excluded from Scouse identity (Christian, 2008; Boland, 2010).

In 1981, in response to 'unemployment, thuggish policing and what a later inquiry would call a culture of "institutional racism" in the police towards Britain's black and minority ethnic urban populations' Toxteth erupted (Hunt, 2014: 383). For four nights, and a subsequent six weeks of 'aftershocks' (Frost and Phillips, 2011: 1), people took to the streets of Toxteth. There are several explanations given for the uprising but Hunt's explanation above is a fair assessment that considers the diverse issues at play: unemployment, poor police-community relations, and structural racism (Hunt, 2014: 383). Media reporting of the events through 'banner headlines, dramatic, confrontational photographs, and extended coverage' (Burgess, 1985: 193) was the way that most the population of Britain came to access and to understand the events in Toxteth. The way that the uprising was reported shaped public conception of the events, Toxteth and its residents.

Toxteth is deeply stigmatized within academic literature where it is marked as a 'blemished' district (Hall, 2003: 204; Wacquant, 2008: 238; Pearce, 2013: 2039). It is also popularly stigmatized. For example, in 2014, the website buyagift.co.uk, which sells 'experience days', launched a spoof campaign entitled 'Hate Breaks'. Included among the 'worst places in the world' was Toxteth, described as 'the underbelly of Liverpool' with its 'rows upon rows of derelict houses' (Liverpool Echo, 2014). Readers were also informed that the area is 'long associated with gang and gun crime' (Liverpool Echo, 2014), reinforcing popular and media stereotypes of delinquency, danger and lawlessness. 


\section{Toxteth in the press}

\section{Naming}

Throughout the early part of the $20^{\text {th }}$ century, the name 'Toxteth' had been used by the media at a low-level and the name was associated with negative attributes. However, locally the area was known as 'Liverpool 8'. Jon Snow of Channel 4 news, who was working as a broadcast journalist for ITN in 1981 and reported on the uprising, explains that 'Toxteth was sort of invented by the media and became a very dark word'. He continues that 'it had become toxic Toxteth almost as soon as the news [of the uprising] broke' (Snow, 2017, interview). This is echoed by Ronnie Hughes, a Liverpool-based housing activist who explains that 'we called it Liverpool 8 or L8 and that was a badge of considerable pride...L8 was where exciting culture happened in Liverpool' (2018, interview). The uprising represented a defining moment in the creation of a national identity of the area and that the media chose to brand the area as 'Toxteth' (which already bore some negative connotations) rather than the locally-preferred moniker (which had positive associations) reflects the press' choice not to listen to local voices and, instead, to brand the area 'from-above'. That the name 'Toxteth' has come to gain use among Toxteth residents at all highlights the hegemonic nature of the press that applies a from-above notion of identity.

A former reporter with the Express further affirms this assertion and explains how the press came to invent and name Toxteth:

I can't remember which paper it was...Daily Mail perhaps...I think the story goes that the photographer arrives from London and drives into the area and sees a sign saying 'Toxteth' which was just on the outskirts of that bit of Liverpool, and took a picture of the sign and it became 'Liverpool's Toxteth district' all of a sudden. They used to call it Dingle or Liverpool 8 but you know, then Toxteth stuck as a label for it. (2017, interview).

Here it is apparent that journalists arriving in Liverpool during the uprising took the name of the area from a sign that they saw, rather than talking to residents and finding out how people referred to the area. This tells us that the name and label of Toxteth was largely applied by the media and then absorbed into common parlance and the public discourse, highlighting the power of the media in the process of labelling and in entering a name into the public discourse. Sociologist Alberto Melucci, in his work on the 'power of naming' (1996: 182), argues the power to name rests 
with those in dominant positions in society. ${ }^{4}$ He explains that the media represent such a dominant body and that 'there is no doubt about the capacity of the media system of manipulating news or transforming public and political life into a spectacle of worldwide proportions' (1996: 225). Here he explains the role of the media in contributing to the public discourse in which we all participate. If we take Melucci's thesis and apply it to the naming of Toxteth, we see that the media occupies a position of power in society such that it has an ability to 'name' and to change the contours and language of public discourse.

\section{Negativity}

Of 496 articles mentioning Toxteth between July $3^{\text {rd }} 1981$ and December $31^{\text {st }} 1981,490$ (98.8\%) are negative. Negativity is characterized by a lack of positive features, a smearing or tainting of place through the 'from above' application of unfavourable imagery, language, or semantic/syntactic choices. Ascertaining the overall valence (positivity or negativity) of an article was done by asking the question: is Toxteth represented in a positive, negative light in this story?

The negativity is achieved through the tone of articles, the semantic and syntactical choices, and the choice of angle. In an article in the Guardian on July $6^{\text {th }} 1981$, the author fairly considers the causes of the uprising as a combination of unemployment and racism (Guardian, 1981a). However, the article also paints a stark picture of Toxteth that, from our knowledge of the way that the media influences the minds and attitudes of readers, will likely contribute to a negatively perceived image of the district. Returning to the quote that opened this paper, several motifs are at play. First, we see the visual imagery of devastation as the reporter describes 'smashed windows, looted shops, terrorised local inhabitants, burning cars, buildings on fire, policemen rolling over and over to extinguish the flames on their tunics and hair' (Guardian, 1981a). The description of the physical scars of the uprising serves to conjure up images of a neighbourhood in turmoil. The focus of much of the quotation is on the police who are depicted as under attack from 'hatred'. In this article, the police, as representatives of the British state, symbolize what it is to be British. This is reinforced by referring to them using the colloquial term 'bobbies', which gives to them an

\footnotetext{
${ }^{4}$ A parallel can be seen with the recent from-above re-branding of Liverpool as the 'City of Culture' and a 'destination' city despite the lived reality being far different (Boland, 2013). This highlights the power of naming to overshadow reality.
} 
air of familiarity, whilst referring to those on the streets only as the abstract 'hatred'. The article leaves readers with a view of those rebelling as brutal attackers against Britain and British values.

Negativity is also applied through ironic and supposedly humourous accounts in the press. Miles Kingston, writing in the Times in October 1981 writes a spoof article about Christmas postage dates suggesting that he has early access to last postage dates for the Christmas season. For postage on October $23^{\text {rd }}$ he lists among others, 'the Iran-Iraq war zone, Christian Beirut, downtown Kabul, Harlem above $125^{\text {th }}$ Street, Toxteth' (Kingston, 1981). Here we see that Toxteth is symbolically inserted among warzones and areas of civil strife. Implicit in this juxtaposition is the suggestion that Toxteth, too, is an area of war and strife. It is to be perceived in the public imagination as just as dangerous as either Harlem, which had seen riots during the 1960s and 70s, or as warzones of the Middle East where lives were being lost through civil and international wars.

Articles with a negative valence were also formed through the use of tag-phrases-short descriptors that serve to accentuate the stigmatizing imagery in the piece and they either precede or succeed the name 'Toxteth'. These tag-phrases are most commonly used in the tabloid press in the Financial Times where usage hovers around 25\%. Generally, the reporters interviewed argued in favour of the use of tag-phrases as space-savers but agreed that they led to clichéd views of people and places. Overall, across all papers, tag-phrases are used in 15\% of all articles and are often used in press to convey information and meaning where space is limited and, as such, tell the reader what traits to associate with Toxteth. The tag-phrases fall into two categories: those that relate to the characteristics of the area and those that reinforce the image of a place scarred by 'riots'. In the first category, these tag-phrases relate largely to the ethnic composition of Toxteth. Characteristic-based tag-phrases include describing Toxteth as 'the multi-racial area' (Cooke, 1981), and 'immigrant area' (Crowther and Chesworth, 1981), which give an image of a geographical 'other' defined by the presence of social and ethnic 'others'. The tag-phrases relating to the uprising range from the straightforward 'the Toxteth riot area' (Aitken et al, 1981) to the more poetic 'wilderness of despair' (Young, 1981). Tag-phrases provide readers with a ready-made image of Toxteth and contribute to the negative valence of the article.

The press employs negativity as part of the pathological discourse that forms stigma surrounding Toxteth. By using negative visual imagery, juxtaposition, and tag-phrases, the press creates a vision 
of Toxteth that problematized. In the articles about Toxteth, crime, disorder and deprivation are normalized, meaning that the poor conditions of Toxteth and the character of a small population of the residents are made to seem 'natural' and unquestioned. It is shown to be a place of danger, deprivation, and damage.

\section{Oppositionality}

The previous section hinted at some of the techniques of negativity that juxtapose Toxteth with representatives of British values to highlight Toxteth's difference: this is the basis of what I term 'oppositionality'. Oppositional behaviour is described by the American Academy of Child and Adolescent Psychiatry as an 'ongoing pattern of uncooperative, defiant, and hostile behavior toward authority figures' (AACAP, 2011: 1). While this description is generally used as part of the diagnostic criteria of Oppositional Defiant Disorder (ODD), a condition that affects young people, I note that as part of its pathological gaze, the press constructs Toxteth as bearing these same characteristics. Toxteth and its residents are shown as being defiant, unwilling to cooperate, and deliberately antagonistic. Indeed, the press constructs Toxteth as being 'opposite' to the rest of society-meaning that it is different and in some way deviant from social norms-but also as 'oppositional'-meaning that it is inherently maladjusted and wilfully contrary.

The press invoke oppositionality when comparing the residents of Toxteth to the royal family as seen in this extract:

If the shattered shop windows of Toxteth remind us of humanity's greed, selfishness and imperfection, this marriage of two young people reminds us of the best, the freshest, the most idealistic of human impulses (Lacey, 1981: 9).

Not only do we see the broken windows metaphor being invoked again but we also see that the article tells us that everything that the marriage of Charles and Diana is shown to be, Toxteth is positioned as opposite. Where their love is 'fresh' and 'idealistic', the 'riots' are based on greed and imperfection. Here Toxteth is framed as being in opposition to Britishness. 
Another way in which the press constructs an oppositional Toxteth is through the creation of a 'mob' and referring to the uprising as 'riots'. By describing those on the streets as engaging in a riot or behaving as a 'mob', the press devalues the identity and claims of those revolting and, instead, symbolically forms an amorphous group that does not have legitimate claims. These terminological choices work in tandem with the overriding political ideology of the time. Roger Fowler explains that 'the Conservative government in office since 1979 represented public uprising as straightforward criminality, a view which the media supported by constantly speaking of "riots", "mobs", "violence"; the government's response was to strengthen the powers of the police and of the courts' (1991: 135). Of the 496 articles, more than 77\% frame Toxteth in 1981 as being 'riotous', consistently reaffirming this view of events. This might be explained by the fact that the journalists interviewed for this study largely perceived that the events were riots, suggesting that, in van Dijk's language, reporters' models were transmitted through the text.

By framing the uprising as a riot and those on the streets as a mob, the press implicitly informs readers that those revolting are in the wrong. Karen Cerulo explains that the media put forth 'public images of right and wrong' (1998: 141); overwhelmingly the violence that is depicted as 'wrong' is the violence of the marginalised. Structural and symbolic violence by the dominant elite is ignored (Barak, 1994). Press structuring of the 'riots' eliminates from the discourse any possibility that those on the streets had legitimate concerns and grievances regarding racial disadvantage, which had, in fact, been identified prior to the uprising but which were not acted on or reported on (Hodges, 1981: 2). Darnell Hunt's study of the Los Angeles 'riots' makes similar conclusions; the media focus on the criminal aspects of the events without considering the structural causes (1997). By criminalising the events in Toxteth-and in Los Angeles-the media fail to ask important questions about why violence is occurring and shows those on the streets as wilfully disobedient against accepted social norms.

On $7^{\text {th }}$ July, two reporters continue the images of war, describing 'the savagery of the pitched battle' in which the 'mob screamed, the buildings roared in flames and a hail of missiles beat a non-stop drum roll on the police shield wall' (Osman and Timmins, 1981: 4). Here the mob is painted as savage, and exerting a direct threat and unwillingness to comply with the state, as represented by the police who are under fire from the wayward mob. The reporters add that they saw 'an awful picture of anarchy' with 'looters of all ages and both sexes, black and white, some wearing Balaclava masks and others handkerchiefs or black plastic bags across their faces rushing 
up within yards of the police line to hurl petrol bombs, bricks, bottles and lengths of uprooted iron railings' (Osman and Timmins, 1981: 4). Here, those revolting are pitted against the police as representatives of law and order, but this time not only is the visual imagery of danger and thuggery strong, but the protestors are described using particular semantic choices. They are described as exhibiting signs of anarchy, suggesting that they are against the system and pose a threat to it: they are a direct challenge to the state as opposed to rebelling against 'the oppressive and most disturbing area of racial disadvantage in the United Kingdom' (Hodges, 1981: 2).

\section{Stranger-making}

The final mechanism that the press uses to stigmatize place as part of the pathologizing gaze is what I term 'stranger-making'. I draw on Georg Simmel's notion of the stranger who 'is near and far at the same time' (Simmel, 1908: 2): near in spatial proximity but far in terms of social distance. The press portrays Toxteth's residents as being spatially fixed in the geography of Britain but socially distant from the rest of the population and it does so in two ways: through comments about difference and through silencing.

Simmel's conception of the stranger can be particularly helpful when understanding notions of foreignness, which feed into the press construction of Toxteth. Through tag-phrases, we are told that Toxteth is an immigrant area' (Crowther and Chesworth, 1981; Osman et al, 1981: 1), the 'multi-racial area' (Cooke, 1981), an' inter-racial community just south of the city centre' (Halsall, 1981: 1), and 'virtually a black ghetto' (Mirror, 1981a: 13). These tag-phrases serve to stigmatize Toxteth. Rather than stating that Toxteth is 'bad' in some way (what would amount to territorial stigma through negativity), the press casts Toxteth as the home to strangers who have 'come[s] today and stay[s] tomorrow' (Simmel, 1908: 1). Toxteth is referred to in these examples using spatially fixed language such as a 'community just south of the city centre' and 'ghetto', both of which give a spatial fixity to Toxteth, but the difference and social distance is cast through references to the racial difference of Toxteth and its residents. This stranger-making is deeply ingrained in Liverpool with relation to the Liverpool-born Black community who have historically been marginalised and omitted from Scouse identity (Christian, 2008; Boland, 2010).

Simmel explains that a characteristic of the stranger is that he has not belonged to it from the beginning, that he imports qualities into it, which do not and cannot stem from the group itself 
(Simmel, 1908: 1) and, through terminological choice, the press constructs the stranger as differing in origin, not sharing a common Britishness. For example, the terms 'immigrant' (Crowther and Chesworth, 1981; Osman et al, 1981: 1) or 'Liverpool's largest coloured community' (Guardian, 1981b: 2) construct Toxteth residents as bearing a different social and spatial origin and, in so doing, make strangers out of them. In this way, Toxteth is cast as a place of strangeness and difference. It is shown to belong to the British Isles but not to Britishness as it remains distant and marginal.

Another way in which the press structures Toxteth and its residents as strangers is through the silencing of the voices of Toxteth residents. ${ }^{5}$ Social distance, which is central to the concept of the 'stranger' is 'usually measured by the amount of social contact between groups' (Mayhew, 2015). The press, by silencing Toxteth residents and not making their voices part of the main discourse about the uprising, keeps Toxteth set aside from the rest of society and structures Toxteth and its residents as being spatially fixed but voiceless and socially separate from the mainstream 'us'.

Of the 496 articles written between the start of the uprising in 1981 and the end of the year, only 48 included a quotation from a resident of Toxteth. Twenty-five of those articles included quotations from both a Toxteth resident and an outsider (police, policymaker, politician etc.) and only 23 articles interviewed a Toxteth resident solely. Conversely, 281 of the 496 reports (56.7\%) interviewed an outsider solely, showing an imbalance in how the residents of Toxteth were represented. It is notable that $33.7 \%$ of the articles under study did not include any quotations from either outsiders or residents, raising issues about the blending of opinion and fact.

Reporters, commentators and politicians interviewed for this study offered many reasons for the almost blatant omission of the views of Toxteth residents. An editor of a British current affairs news magazine suggests that there is a personal safety angle involved in the choice to interview residents during a major public disorder. He explains 'you can get the shit beaten out of you in somewhere like Toxteth if you go around saying, "what's happened?"” (2017), suggesting that often it may be deemed too dangerous to interview residents or insider sources and, instead, it is a safer

\footnotetext{
${ }^{5}$ Not all residents of Toxteth were involved in the uprising, of course, but I argue that the smear of Toxteth in the press tainted all residents.
} 
option to talk to official figures. David Rose, a former Guardian reporter adds to this, explaining that fear of an area and the potential danger that could be encountered may have put off some journalists from venturing too far into Toxteth to seek out the voices of residents. He reflects that in the Brixton uprising photographer David Hodge was killed, highlighting the danger posed to reporters in areas of disorder. He reflects that 'it's much, much easier if you go and talk to the cops: cops [are] only too happy to you know, put out their version' (2017). So, we see that often reporters made the conscious decision to keep away from the areas at the centre of uprising and, as such, the voices of residents are silenced.

Sometimes keeping away from the area was not the choice of the reporter but was necessitated by time and location constraints. A former Times journalist who I interviewed and who wrote on the aftermath of the Toxteth uprising explained that 'I honestly don't think I went there', explaining that much of the on-the-ground observation came to the newsroom from Press Association wires that were to be incorporated into reports written away from the scene of the events. This explains that often residents were not interviewed because reporters were not always in place to interview them. Conversely, it was likely far easier to contact policymakers, politicians and key outsider figures who were available for interview by telephone or who had made public statements that were accessible to reporters.

Conversely, it appears that many reporters did visit Toxteth during and after the uprising. A former Mirror journalist explained that talking to residents was the 'first thing we did there'. Yet, despite this, the fact stands that only 48 articles ( $9.7 \%$ of all articles) included a quotation from a resident. Martin Wainwright, former Northern Editor of the Guardian explained that often residents were interviewed but that their quotes would be the first to be edited out because they are seen to only represent one person's opinion as opposed to the view of a politician, for example, who is seen to represent the population more generally). In this way, outsiders who are spatially remote from Toxteth are given a voice in the affairs of the area. They are portrayed as being less socially distant than the residents of Toxteth.

Semantic decisions to refer to those on the streets and residents of Toxteth as a 'mob' has implications for the silencing of insider sources. By electing to use the label 'mob' to describe the crowds, reporters are supporting the view that those uprising are criminal and deviant and, as such, 
it is no surprise that their voices are omitted from reports: it would be highly unusual for criminals to be given the chance to justify their actions in the press. David Rose, former Guardian reporter, agrees with this interpretation and refers to Home Secretary Douglas Hurd's (1985-1989) response to the uprising that took place in Birmingham in 1985. Hurd famously stated that the Handsworth uprising was 'not a cry for help but a cry for loot' (Reitan, 2003: 109). Framing those on the street as a mob means that, through oppositionality, Toxteth's residents are placed outside the status quo. This contributes to the process of stranger-making as the mob are identified as being spatially tied but socially distant to and removed from the rest of the population.

A final possibility for the silencing of Toxteth residents relates to racial othering. Toxteth has long had a large black population (Gifford, 1989) and, as such, there is also the possibility that silencing Toxteth residents arises from the general media silencing and stereotyping of black populations in mass media (Entman, 1994). This fits with the larger historical social structure in which the largely white powerful elite and middle class in Britain has stigmatized and categorized black Britishness as a form of 'otherness'. ${ }^{6}$ Entman suggests that there is not an overt racism inherent in the media but rather racial silencing and stereotyping reflects "political and social reality" (1994), tying in with Chomsky's assertion that we are conditioned into society's filtering system from childhood (Requiem for the American Dream, 2015).

Regardless of the reason for their omission, it is apparent from data that residents' voices are missing from press coverage of the uprising and this is inimical to both the quality of the coverage, which is missing an on-the-ground element, and to the credibility of the picture presented of Toxteth. The coverage assumes that the official voices speak the truth and do not acknowledge that there are multiple realities of what is happening in Toxteth. The message that the omission puts forth is that the residents of Toxteth do not warrant their voices to be heard and the voices that should be central to the story of Toxteth are, in fact, marginalized. They are removed from the social discourse, rendering them unheard strangers-geographically tied but socially set adrift from the mainstream discourse surrounding the uprising.

\footnotetext{
${ }^{6}$ Mark Christian (2008) offers an account of the crafting of the Fletcher Report in Liverpool in 1930 that demonstrates racial othering in philanthropic work.
} 


\section{Conclusion}

All four techniques - naming, negativity, oppositionality, and stranger-making — can be seen as means of accomplishing territorial stigmatization in the media. Through naming, the press externally brands a place onto which negative imagery and oppositional traits can be attached. Through negativity, the press paints a place as lacking positive attributes, smears it with tainting language and negative visual imagery, resulting in the discursive construction of an area imbued with aversiveness. Use of negative visual imagery, juxtaposition, and tag-phrases, all create a readymade vision of Toxteth that is problematized. Oppositionality, as employed by the press, constructs an area and its residents as being wilfully contrary to the status quo and the rest of society - the status quo that the media is so anxious to maintain. Through stranger-making, the press makes the residents and the place into a remote and voiceless entity that is socially distant from the rest of mainstream society. The strangeness can be understood as threatening but, more so, it conjures up ideas of not belonging and hierarchization of social strata, tacitly placing Toxteth residents at the bottom of the social strata and outside social norms. Where naming, negativity, and oppositionality externally impose an identity and image onto Toxteth, stranger-making denies internal identity construction. This study has highlighted some of the ways in which territorial stigma is enacted by the media in order to elicit fear among readers and, crucially, to uphold the status quo in society that privileges powerful elites. Examining how and why stigma of place emerges helps us to address the gap in research regarding the production of stigma (Devereux et al; 2011a; 2011b). Moreover, this paper serves to offer a thorough examination of how language is used in the stigmatizing process.

This paper has emphasised the negative aspects of the media — what can happen when stigmatising coverage becomes the norm and when the media operate on behalf of powerful elites and not on behalf of the public. There are countless examples of the media serving the public, using reporters' investigative powers to unearth controversies and scandals. Reporters and journalists are not ogres and do not always deliberately put forth biased reports; most of the journalists interviewed for this study acknowledged the damage done by clichéd tag-phrases and regretted the damage caused. Rather, the media system is entangled in an unconscious system in which it is part of a structure that enables powerful voices and views of society to dominate (Herman and Chomsky, 1988). 
In the United States, the Society of Professional Journalists abides by a code of ethics that upholds the importance of giving voice to the voiceless (Society of Professional Journalists, 2018). Whether this code of ethics ensures that the voiceless are heard any more than they are on this side of the Atlantic remains to be seen. However, underscoring this point moves journalism in a more ethical, critical, socially responsible direction. While academics hold media to account and critique the press' stigmatization of people and places, the media itself can be more responsible by listening to local voices, by embracing investigative journalism, and by consistently reporting facts rather than opinion. Ultimately, by determining to use the media to give voice to the voiceless, the media can hold power to account and aid in creating a more equitable society. 


\section{References}

AACAP. (2011) Children with Oppositional Defiant Disorder [Online], Washington, D.C., American Association of Child and Adolescent Psychiatry. Available at https://www.aacap.org/App_Themes/AACAP/docs/facts_for_families/72_children_w ith_oppositional_defiant_disorder.pdf (Accessed 27 April 2018)

Aitken I, Mackie L and Morris M (1981) Scarman riot brief takes in Toxteth and Southall. Guardian, 8 July, 1.

Barak G (1994) Media, society and criminology. In Barak G (ed) Media, Process, and the Social Construction of Crime. New York: Garland, 3-48.

Belchem J (2000). Merseypride. Liverpool: Liverpool University Press.

Belchem J (2006) Timeline of notable events. In Belchem J (ed) Liverpool 800: Culture, Character \& History. Liverpool: Liverpool University Press, 510-517.

Bingham A and Conboy M (2015) Tabloid Century. Oxford: Peter Lang.

Boland P (2008) The construction of images of people and place: Labelling Liverpool and stereotyping Scousers. Cities 25(6): 355-369.

Boland P (2010) Sonic geography, place and race in the formation of local identity: Liverpool and Scousers. Geografiska Annaler 92(1): 1-22.

Boland P (2013) Sexing up the city in the international beauty contest: the performative nature of spatial planning and the fictive spectacle of place branding. The Town Planning Review 84(2): 251-274.

Bryman A (2012) Social research methods. 4th edn. New York: Oxford University Press.

Burgess J (1985) News from Nowhere: The Press, the Riots and the Myth of the Inner City. In Burgess J and Gold J (eds) Geography, the media and popular culture.

London: Croom Helm, pp. 192-228.

Cerulo K (1998) Deciphering Violence. Routledge: New York.

Christian M (2008) The Fletcher Report 1930: A Historical Case Study of Contested Black Mixed Heritage Britishness. Journal of Historical Sociology 21(2/3): 213-241.

Cooke H (1981) Maggie's Toxteth outburst. Express, 31 July, 2.

Cooper P (1985) Competing explanations of the Merseyside riots of 1981. British Journal of Criminology 25(1): 60-70.

Crowther A and Chesworth M (1981) Mob violence. Mirror, 6 July, 5.

Devereux E, Haynes A and Power MJ (2011a) At the edge: Media constructions of a stigmatised Irish housing estate. Journal of Housing and the Built Environment 26(2): 123142. 
Devereux E, Haynes A and Power MJ (2011b) Tarring everyone with the same shorthand? Journalists, stigmatization and social exclusion. Journalism 13(4): 500-517.

Entman R (1994) Representation and Reality in the Portrayal of Blacks on Network Television News. Journalism and Mass Communication Quarterly 71(3): 509-570.

Foucault M (1998). The will to knowledge (The history of sexuality volume 1). London: Penguin.

Fowler R (1991). Language in the news. London: Routledge.

Frost D and Phillips R (2011) Liverpool '81. Liverpool: Liverpool University Press.

Galtung J and Ruge M H (1965). The structure of foreign news. Journal of Peace Research, 2(1), pp.64-91.

Gifford A, Brown W and Bundey R (1989) Loosen the Shackles: First Report of the Liverpool 8 Inquiry into Race Relations in Liverpool. London: Karia Press.

Guardian (1981a) A detritus that won't wash away. 6 July, 10.

Guardian (1981b) Youth breaks back in Toxteth rioting. 29 July, 2

Hall D (2003) Images of the City. In: Munck R (ed) Reinventing the City?: Liverpool in Comparative Perspective. Liverpool: Liverpool University Press, pp.191-210.

Halsall M (1981). Whitelaw 'unaware’ of Toxteth’s social problems. Guardian. 9 July, p. 4.

Hartmann P and Husband C (1974) Racism and the mass media. London: Davis-Poynter.

Hastings, A. (2004). Stigma and social housing estates: Beyond pathological explanations. Journal of Housing and the Built Environment, 19(3), pp.233-254.

Herman E and Chomsky N (2010) Manufacturing consent. Vintage Digital.

Hodges L (1981) Warning about Liverpool came too late. Times, 7 August, 2.

Howe G (1981) Chancellor of the Exchequer minute to MT, 11 August.

Hunt D (1997) Screening the Los Angeles 'riots'. Cambridge: Cambridge University Press.

Hunt T (2014) Ten Cities that Made an Empire. Penguin

Kelling GL, Wilson JQ (1982) Broken windows: the police and neighborhood safety. Atlantic Monthly. March. 249(3): 29-38

Kennard M (2013) BB interviews...Noam Chomsky. Ft.com. Available at: 
https://www.ft.com/content/bcdefd38-3beb-3506-b24c-82285ac87f6c (Accessed 24 Jan. 2018).

Kingston M (1981) Moreover.... Times. 21 October, 14.

Knowles C (2003) Race and social analysis. London: SAGE.

Lacey R (1981) A rich love the whole nation can share. Express, 20 July, 8-9.

Liverpool Echo (2014) Online gift company sorry for saying Toxteth was one of worst places in world to visit. Available at: https://www.liverpoolecho.co.uk/news/liverpoolnews/toxteth-apology-gift-company-saying-7131932 (Accessed 26 Jan. 2018).

McCombs M E and Shaw D E (1968). The Agenda-Setting Function of Mass Media. The Public Opinion Quarterly 36(2): 176-187.

McIntyre-Brown A (2001) Liverpool the first 1,000 years. Liverpool: Garlic Press.

Madsen H (1992) Place-marketing in Liverpool: a review. International Journal of Urban and Regional Research 16(4): 633-640.

Mayhew S (2015). Oxford dictionary of geography. Oxford: Oxford University Press.

Melucci A (1996). Challenging Codes: collective action in the information age. Cambridge: Cambridge University Press.

Murden J (2006) 'City of Change and Challenge': Liverpool since 1945. In: Belchem J, ed, Liverpool 800. Liverpool: Liverpool University Press, pp.393-485.

Nassy Brown J (2005). Dropping Anchor, Setting Sail: Geographies of Race in Black Liverpool. Princeton: Princeton University Press.

Osman A and Timmins N (1981) Greed and ferocious violence mark a collective madness. Times, 7 July, 4.

Osman A, Timmins N and Tendler S (1981) Police use CS gas after admitting riot is out of control. Times, 6 July, 1.

Pearce J (2013) Commentary. Environment and Planning A 45(9): 2030-2045.

Reitan EA (2003) The Thatcher Revolution. Oxford: Rowman \& Littlefield.

Requiem for the American Dream (2015). [DVD]. Directed by Kelly Nyks, Peter D. Hutchison and Jared P. Scott. PF Pictures.

Schemer C (2012) The Influence of News Media on Stereotypic Attitudes Toward Immigrants in a Political Campaign. Journal of Communication 62(5): 739-757.

Scraton, P (2007) Power, conflict and Criminalisation. Abingdon: Routledge.

Simmel G (1908). The Stranger. In: G. Simmel, ed., Sociology. 
Society of Professional Journalists. (2018). SPJ Ethics Week: April 23-27, 2018. [online] Available at: https://www.spj.org/ethicsweek-whoarejournalists.asp [Accessed 17 Oct. 2018].

Tsfati Y and Cohen J (2003). On the Effect of the "Third-Person Effect": Perceived Influence of Media Coverage and Residential Mobility Intentions. Journal of Communication, 53(4), pp.711-727.

Van Dijk T (1996) Power and the news media. In: Paletz D (ed) Political communication in action. Cresskill, NJ: Hampton Press, pp.9-36.

Wacquant L (2008) Urban Outcasts: A Comparative Sociology of Advanced Marginality. Cambridge: Polity Press.

Wacquant L (2007) Territorial Stigmatization in the age of advanced marginality. Thesis Eleven 91(1): 66-77.

Wilks-Heeg S (2003) From World City to Pariah City? Liverpool and the Global Economy, 18502000. In: Munck R (ed) Reinventing the City? Liverpool in Comparative Perspective: Liverpool University Press, pp. 36-52.

Young (1981) Troubleshooter ropes in the investors. Times, 3 August, 3. 